\section{Federation University ResearchOnline}

\section{https://researchonline.federation.edu.au}

Copyright Notice

This is the peer-reviewed version of the following article:

S. Kumar, N. Das and S. Islam, "Performance evaluation of a process bus architecture in a zone substation based on IEC 61850-9-2," 2015 IEEE PES Asia-Pacific Power and Energy Engineering Conference (APPEEC), 2015, pp. 1-5.

Available online: https://doi.org/10.1109/APPEEC.2015.7381017

Copyright ( 2015 IEEE. Personal use of this material is permitted. Permission from IEEE must be obtained for all other uses, in any current or future media, including reprinting/republishing this material for advertising or promotional purposes, creating new collective works, for resale or redistribution to servers or lists, or reuse of any copyrighted component of this work in other works. 


\title{
Performance Evaluation of a Process Bus Architecture in a Zone Substation based on IEC 61850-9-2
}

\author{
Shantanu Kumar, ${ }^{1,3}$ Member, IEEE, Narottam Das, ${ }^{1,2}$ Senior Member, IEEE, and Syed Islam, ${ }^{1}$ Senior Member, IEEE \\ ${ }^{1}$ Department of Electrical and Computer Engineering, Curtin University, Perth, WA 6845, Australia \\ ${ }^{2}$ School of Mechanical and Electrical Engineering, University of Southern Queensland, Toowoomba, QLD 4350, Australia \\ ${ }^{3}$ Asset Performance Department, Western Power, Perth, WA 6000, Australia \\ e-mails: shantanu.kumar@postgrad.curtin.edu.au,narottam.das@usq.edu.au, and s.islam@curtin.edu.au
}

\begin{abstract}
Ethernet communication has been the back bone of high speed communication in digital substations from protection relaying, control and automation perspective. Major substation manufacturers have been constantly upgrading softwares and adding new features in their Intelligent Electronic Devices (IED's) to carry out multiple functions in process bus devices. This paper presents simulation results with respect to the delay in packets transfer in an Ethernet environment. Understanding the delay in packet transfer of Generic Object Oriented Substation Event (GOOSE) and Sampled Values (SV) shall assist the user in understanding the substation automation, control and protection of substation primary plants such as current transformers (CT's), voltage transformers (VT's), circuit breakers etc. connected in the network during a fault condition Conventional substation uses Merging Units (MU's) to communicate with the IED's featuring IEC 61850-9-2 standard. This standard exhibits transparency and standardization of data communication while addressing issues related to reliability, packet sharing, and maintainability, etc. However, process bus architecture is yet to be widely accepted in the industry and needs further validation due to lack of confidence. This paper evaluates the performance of a digital protection scheme in a zone substation operating at 132kV, featuring IEC 61850-9-2 IED's and using an optimized network engineering tool (OPNET) simulator. Understanding the delay in receiving time critical GOOSE and sampled value $S V$ messages from protection perspective is critical as loss of data could cause mal-function in the protection jeopardizing vital substation plants.
\end{abstract}

Index Terms-Ethernet, GOOSE, IEC 61850-9-2, IED's, Sampled Values, Merging Units.

\section{INTRODUCTION}

$\mathrm{F}$ aults occurring in a power system must be cleared immediately in order to meet the stability requirement. However, the complexity in wiring and conventional method of installation of copper wire has caused time consuming diagnostics in a fault scenario. The conventional substations secondary wiring has been improved in a digital substation using fiber optic cable connection to IEDs due to technological advancement. This has resulted in saving of the project man-hour, and reduction in installation and shutdown time.Progress is underway based on IEC 61850-9-2 standard to address multivendor integration, increased safety, reduction in equipment size, dependability in protection and control
(P\&C). Ethernet based $\mathrm{P} \& \mathrm{C}$ reduces project cost, restores secondary system quicker and lowers maintenance costs considerably. Digital substations have the potential to optimize through nonconventional instrument transformers (NCIT) and process bus due to its advanced features, such as increased availability, reduced cabling/auxiliary contacts, simplified signal marshalling for testing and diagnostics. It can even record faults making fault recorders obsolete in the substation. Further, use of NCITs in digital substation gives increased safety due to absence of oil and saturation issues, reduction in noise due to non-presence of iron core and Ferroresonance, high accuracy in protection and metering. As substations operate round the clock and rarely shuts down for maintenance, it is imperative that the plants have reduced lifecycle and downtime costs during its design life in a substation. In these challenging conditions, file and data transfer over Ethernet in a digital network, is of vital interest to the operator as loss of data could spell disaster in a protection scheme based on IEC 61850-9-2, featuring process bus parameters. Utility and Industry have been working towards establishing a reliable and fast communication network, between substation switchyard assets and substation automation systems (SAS) which could monitor, record and clear system disturbances in the least possible time exhibited in Table-I.

In the overall scheme, SAS and communication topologies play an important role in a digital substation, based on IEC 61850. However, in spite of the promises that it holds for future, there are few short comings encountered in IEC 61850 using Ethernet communication linking devices in a digital environment which are not entirely without issues. High availability and single point failure could compromise mission critical P\&C applications. Although, IEC 61850 standard lays down many guidelines in communication in many sections of IEC 61850 for bay and process level components, yet it fails to address issues related to loss of data packets at nodes in the topology connected to IED's and switches [1]. Further, the timing requirement of a protection system to operate being critical, such as interlocking and blocking, accomplishment of data transfer remains a challenge within $4 \mathrm{~ms}$ and exhibited in Table-I.

Fig. 1A and $1 \mathrm{~B}$ exhibits the difference in wiring in a conventional which is more cumbersome and costly as opposed to the installation of fiber optic cabling in a digital 
substation which offers significant advantage to the business, in terms of cost and faster project completion time. Also, It has been proven application of process bus architecture in a green field substation could save the business up to $1 / 3^{\text {rd }}$ of the man-hours required to complete a similar secondary wiring installation and termination in a conventional substation.

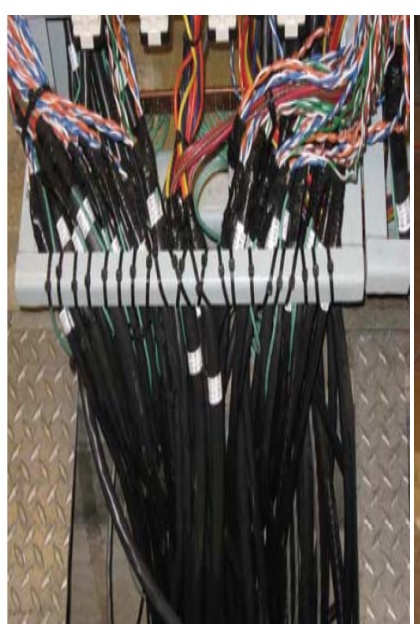

Fig. 1A: Traditional wiring.

Fig. 1B: Process bus wiring.

Table-I: Communication recovery time after a failure based on IEC 61850-5 [2].

\begin{tabular}{|l|c|c|}
\hline $\begin{array}{l}\text { Communication } \\
\text { Partners }\end{array}$ & $\begin{array}{l}\text { Application } \\
\text { Recovery time } \\
\text { (in ms) }\end{array}$ & $\begin{array}{l}\text { Communication } \\
\text { Recovery Time } \\
\text { (in ms) }\end{array}$ \\
\hline $\begin{array}{l}\text { Client - Server } \\
\text { SC to IED }\end{array}$ & 800 & 400 \\
\hline $\begin{array}{l}\text { IED to IED, reverse } \\
\text { blocking, } \\
\text { interlocking }\end{array}$ & 12 & 4 \\
\hline Trip GOOSE & 8 & 4 \\
\hline Bus Bar Protection & $<1$ & seamless \\
\hline Sampled Values & $\begin{array}{l}\text { Less than one } \\
\text { consecutive } \\
\text { samples }\end{array}$ \\
\hline
\end{tabular}

This paper consists of the following sections; section I gives an overview of the standard i.e., IEC 61850-9-2; section II deals with the fundamentals of IEC 61850-9-2. Section III models a typical substation using OPNET software. Section IV reviews the simulation results obtained by OPNET software in a process bus configuration and the section $\mathrm{V}$ concludes the paper.

\section{FUNDAMENTALS OF IEC 61850-9-2}

The MU in process bus architecture forms the backbone of IEC 61850-9-2 standard, which is a device usually located in the digital substation switchyard, installed adjacent to the NCITs as seen in Fig. 4. MU's capture the information from NCITs and converts analog to digital information with the time stamp. In Fig. 2 a process bus and a station bus configuration has been exhibited in the simplest block diagram form. All fiber optics from the field equipment such as CT's and VT's are routed to the station control via MU's. Station bus which interfaces between control centre and field equipments such as disconnectors, earth switches, circuit breakers, power transformers, shares packet data amongst IED's located at process and station level and as shown in Fig. 2.

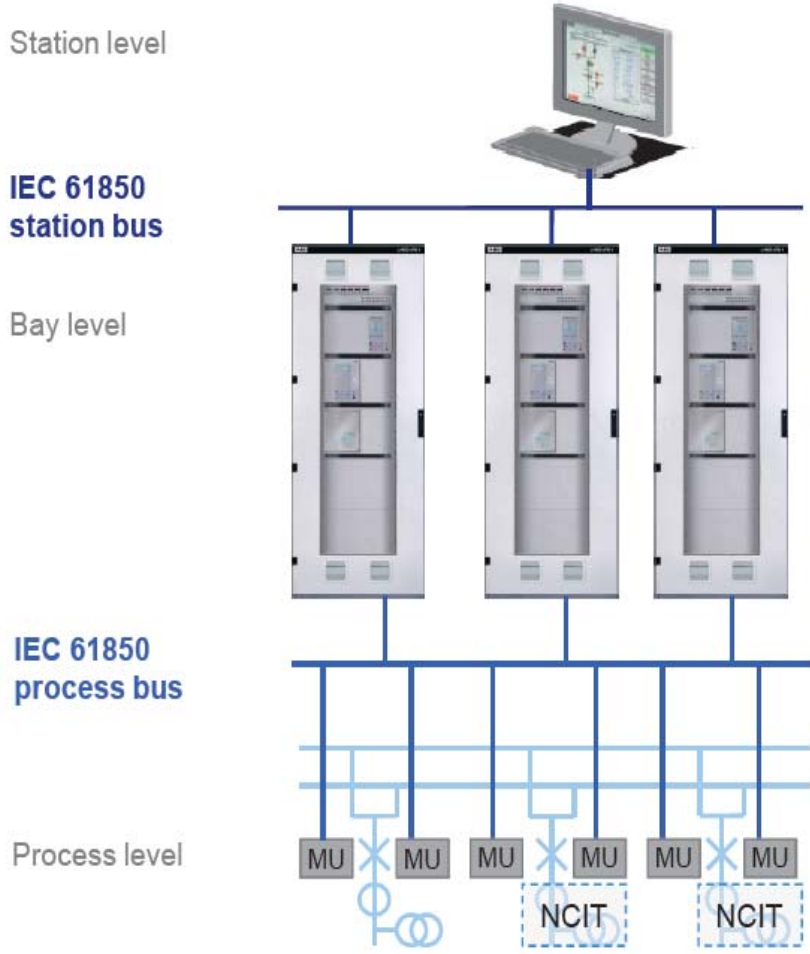

Fig. 2: Process level topology in a $132-\mathrm{kV}$ substation [2].

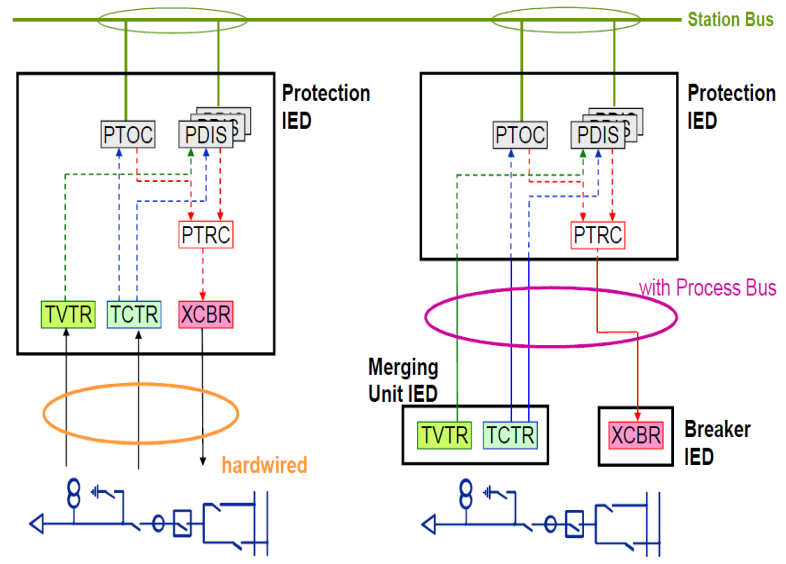

Fig. 3: Logical node arrangement in a zone substation [3].

In station bus type of architecture, data transfer takes place based on IEC 61850-8-1 featuring control, report, GOOSE and file transfer services. In a process bus architecture, based on IEC 61850-9-2, data exchange takes place from field equipment such as NCIT's, conventional instrument transformers, Circuit Breakers (CB's) and IED's for binary state, trip and command. Data exchange takes place between logical nodes (LN) which forms small part of a function as shown in Fig. 3. Additionally, the substation field equipment 
sample currents and voltages from different phases of the field devices and feed to IED's located in the local and main control rooms. The SV service data is transferred based on IEC 61850-9-2 standard, which not only checks for the redundancies in the secondary system but also at the nodes. However, there are few major challenges with respect to pushing out time-critical messages on trip or fault commands, in order to enable data packets to reach the destination in less than 3 4-ms i.e., the GOOSE or SV packets during any traffic condition as shown in Table-I. This is hard to achieve, due to traffic congestion and network topology, but with appropriate architecture, this delay in communication could be mitigated [4].

Fig. 4 exhibits the basic concept and interface with process devices based on IEC 61850-9-2 in the form of block diagram. In this figure, MU carries bulk of information from field devices and interfaces with P\&C IED's. XCBR and TCTR terminologies stand for CB's and CT's and as defined in IEC 61850-7-4 standard.

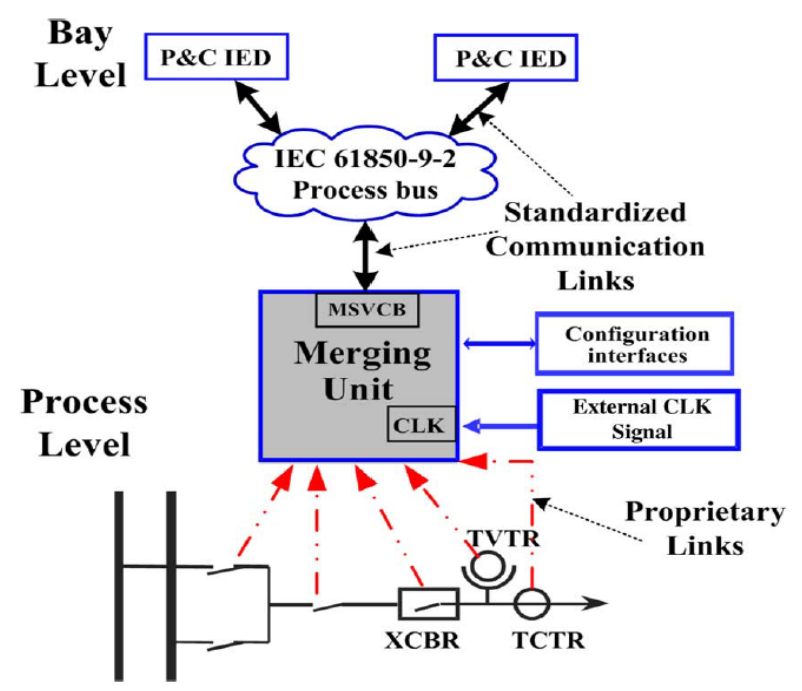

Fig. 4: Basic concept of a process bus in an IEC 61850-9-2 environment [5].

The GOOSE packets in Fig. 4 are transmitted in the network intermittently every second, while SV packets are triggered at the rate of sampling frequency. Fig. 4 also shows MU's where the SV's are sampled according to IEC 61850-92. Current and Voltages are merged in the MU's originating from NCITs, which are located in the substation switchyard. IEC 61850-9-2 standardizes distribution of analog values from MU's in P\&C IED's. Hence, this standard is suitable for all applications from protection, metering and power quality perspective. However, the standard being very broad, could leave the user with a scope for interpretation leading to interoperability issues having multi-vendor proprietary software's. Currently IEC 61850-9-2LE edition defines the application profile of IEC 61850-9-2 and resolves the issue to some extent.

Fig. 5 shows the actual installation of MU's and sensors integrated on a $132-\mathrm{kV}$ CB. In this figure, a typical $132-\mathrm{kV}$ bay consists of $\mathrm{CBs}$ with the MU boxes installed on a common $\mathrm{CB}$ structural support. NCITs has been installed on the $\mathrm{CB}$ bushings which sends digital signals to the process bus IED's via the MU's.

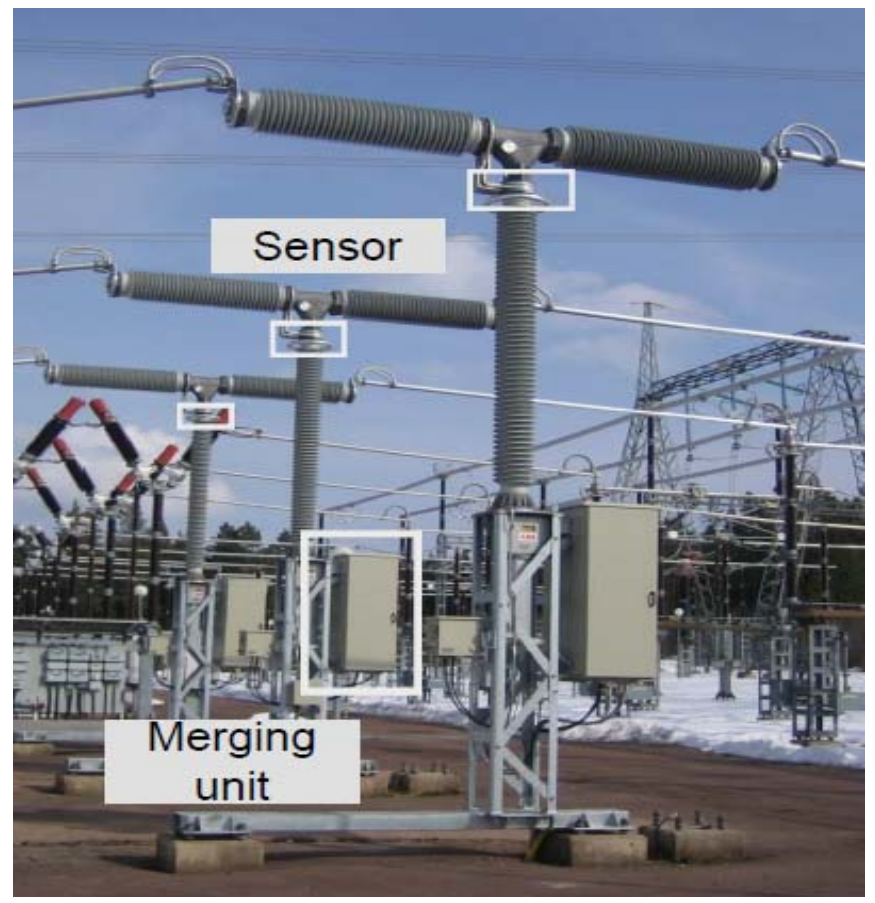

Fig. 5: Live tank Breaker with MU and sensors at site [1].

\section{OPNET MODEL OF IEC 61850-9-2 SUBSTATION}

The advantage of having this standard couldn't be oversimplified more, than to exhibit reduction in cost of long and heavy secondary copper cabling and time taken to install these cables, which is replaced by light weight Ethernet field fiber optic cables to the control room in an IEC 61850-9-2 process bus substation. Further, based on this standard, time critical GOOSE messages and raw sampled values from field equipment facilitate faster communication between switchyard equipment and IED's located in the protection/control building within the permissible time stipulated in the standard. At present, various manufacturers and utilities are working towards having a reliable and redundant communication architecture [1]. This paper evaluates the performance of IED's and MU's connected in a process bus system with multi-vendor devices and operating in IEC 61850-9-2 standard. Many factors such as link, packet service rate, network traffic, affect the performance and considering the importance of the packet loss, the paper focuses on a method to mitigate the loss of packets. The aim of the paper is to evaluate the loss of data packets in a $132 / 11 \mathrm{kV}$ substation and address the issues in the process bus architecture in terms of reliability in protection, distribution of process intelligence, and interface between analog and digital devices in a substation.

\section{Network Topology in a Process Bus Configuration}

A basic single line diagram (SLD) has been exhibited in Fig. 6 which shows a typical $132 / 22-\mathrm{kV}$ zone substation. In this substation, delay of packet transfer performance has been 
investigated of a protection system based on process bus architecture using OPNET simulation. Further, in this zone substation, there are two power transformers feeding two single sections of $22-\mathrm{kV}$ switchboards with a bus coupler in between the two buses having 2 line incomers at 132-kV level.

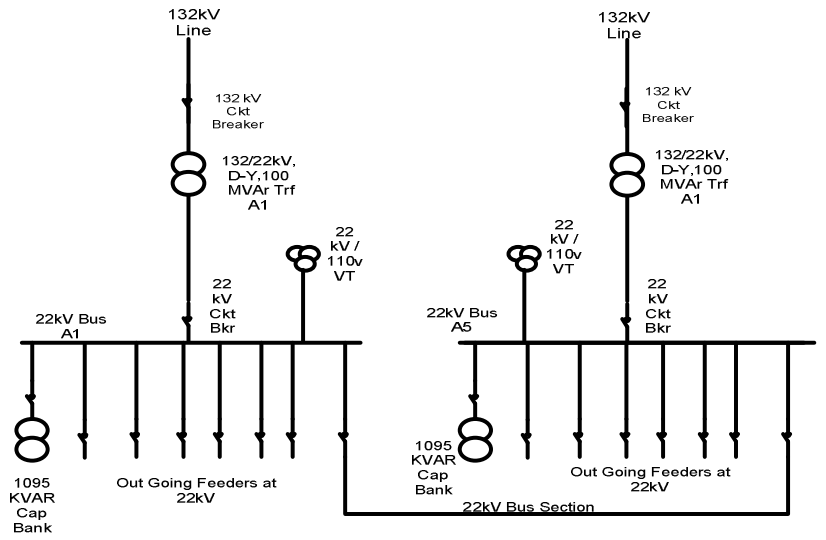

Fig. 6: A basic SLD of a 132/22-kV zone substation.

\section{A) Protection scheme in a block diagram}

The IED's in the block diagram shown in Fig. 7 is for one section of the SLD shown in Fig.6 consisting of one power transformer and CB's. All primary and secondary side of the power transformer have protection IED's connected to LAN bus via MU's deriving current and voltages from CT's and VT's at 132/22-kV.

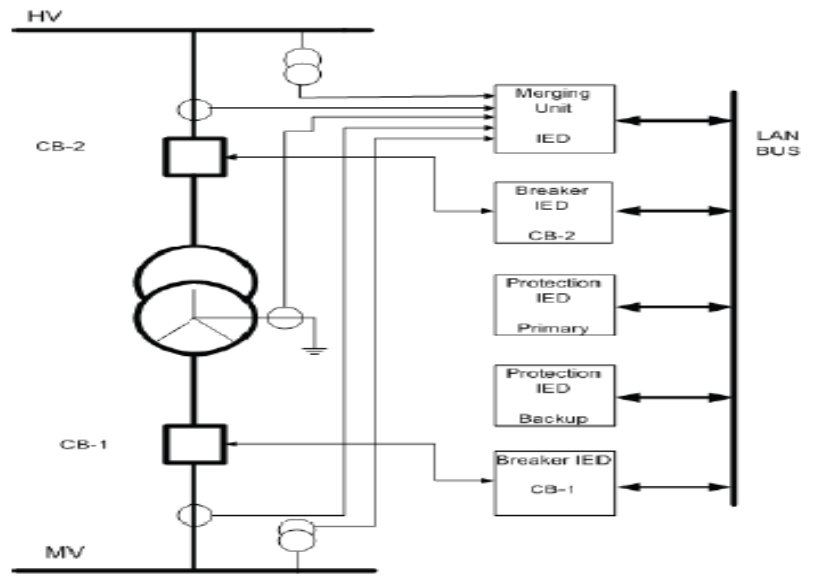

Fig. 7: Block diagram of one section of the SLD of Fig. 6.

In Fig. 7, the block diagram (listed equipment's) has the following features:-

Breaker IEDs

1. Controls Breaker circuit and monitors the CB status

2. It performs Trip/Close command from IED's connected in the process bus system.

Protection and Control IEDs

1. Integrates all substation and control function in the substation.

Merging Units (MUs)

1. Merges all conventional data from a Current and Voltages in the primary and secondary side of a Power transformer
2. Transmits SV's to the network.

Ethernet packets

1. Transmitted in a digital protection system as packets

2. Sends multi cast messages at a defined sample rate, with address and multicast group address.

GOOSE messages

1. Time critical data i.e. trip, block, interlock

2. Does not use TCP/IP protocol in packet transfer

3. Messages are lost by multicasting.

Sampled values

1. Sampling of data collected from instrument transfer from current and voltage transformers or IED's

2. Continuous stream data.

Client server communication

1. Information exchange such i.e. fault, event, measurement

2. Non time critical data.

The benefits accrued in the process bus architecture are basically, the simplicity in wiring and flexibility in changing devices without the hassle of the shutdown of the secondary system.

\section{B) Simulation of protection scheme based on a ring topology}

The $132 / 22-\mathrm{kV}$ zone substation has 30 CT's and 8 VT's. In this substation, 1 MU can configure 1 CB's, 3 CT's and 3 VT's on line side. In total, there are 2 MU's on the primary side of the transformers.

\section{Simulation Results AND Discussion}

Using an OPNET simulator, the overall delay at the nodes of IED's and switches were carried out for GOOSE packets as delay in GOOSE packets could have significant effect on protection system.

Fig. $8 \mathrm{~A}$ and $8 \mathrm{~B}$ exhibits the OPNET ring structure and process model. Using process model data traffic is generated. Embedded within these models lies several programming language in $\mathrm{C}++$ which has not been detailed in this paper for simplicity. GOOSE packet delay is observed at the node of an overall ring topology protection in a 132/22-kV zone substation based on IEC 61850-9-2 standard. The simulation was carried out with the IED's connected on HV and MV side of the power transformer.

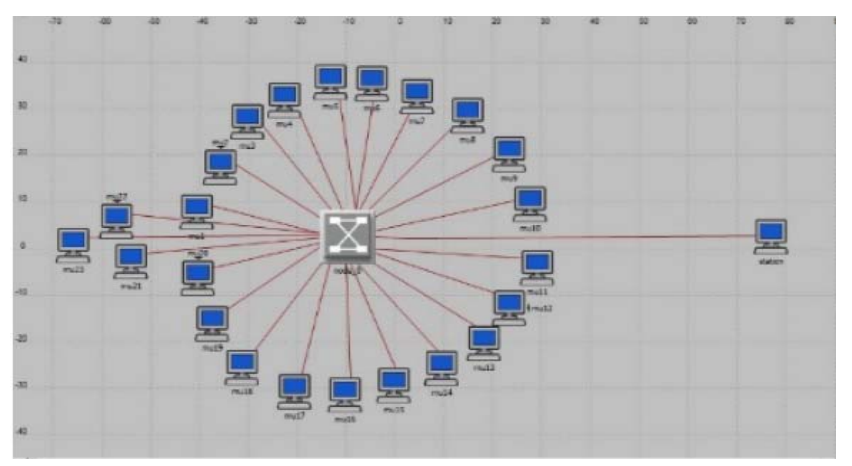

Fig. 8A: OPNET ring structure model. 


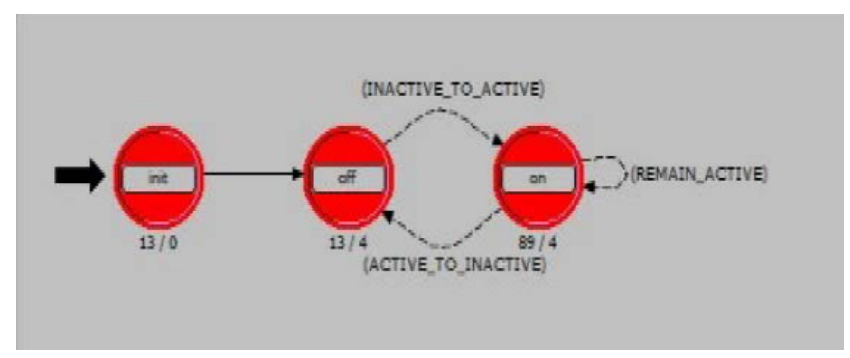

Fig. 8B: OPNET process model.

Fig. 9A and 9B shows the overall and average delay time of data packet transfer to IED's in ring topology. In this ring topology, the average LAN speed considered is $100-\mathrm{Mb} / \mathrm{s}$ as enumerated in Table II.

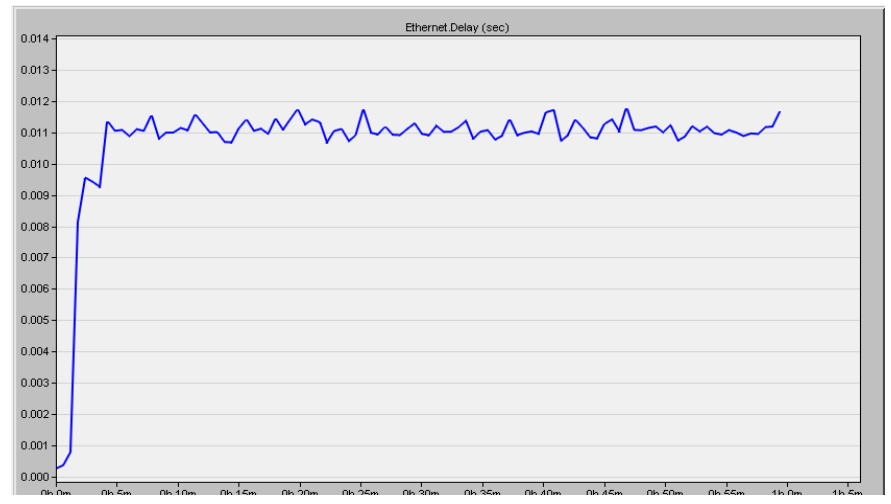

Fig. 9A: Overall GOOSE delay time based in a ring topology.

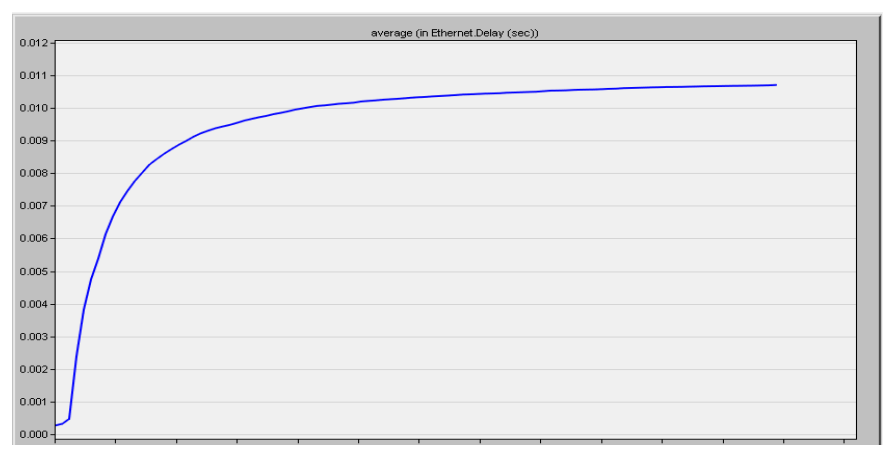

Fig. 9B: Average GOOSE delay time in a ring topology.

The simulation of process bus with MU's and IED's were carried out using the OPNET software having the following parameters as listed in Table II.

Table-II: The parameters used in the OPNET simulation.

\begin{tabular}{|l|c|}
\hline & GOOSE \\
\hline Events & $4,003,753$ \\
\hline Simulated Time (ms) & 30 \\
\hline Average Speed (events/sec) & 762,474 \\
\hline Time elapsed (ms) & 2.33 \\
\hline Duration of simulation (Hrs) & 0.5 \\
\hline DES Log & 4 entries \\
\hline Average LAN speed & $100 \mathrm{Mb} / \mathrm{s}$ \\
\hline
\end{tabular}

It was observed that overall traffic delay at nodes were well within the standard guideline and offered greater reliability in protection. It was also noted that when sampling rates increased from $1920-\mathrm{Hz}$ to $4800-\mathrm{Hz}$, it caused more delay and loss of packets per second. The above simulations were with IED's having single port node models.

\section{CONCLUSION}

In conclusion, traditional copper wires connecting relays in a conventional substation worked well at bay and process level but in order to make it more cost effective and speed up the project implementation time, it is worthwhile considering application of IEC 61850-9-2 process bus architecture.

In this paper, a simulation carried out on a process bus architecture based on IEC 61850-9-2 standard exhibits delay and loss of packets which could have significant effect on the reliability of the protection system in a SAS network. The performance of GOOSE were analysed and impact on communication link data rate at $100-\mathrm{Mb} / \mathrm{s}$ were evaluated. During the performance simulation, it was observed that increasing the SV's frequencies caused higher packet losses per second.

Based on the simulation results in a typical $132 / 22 \mathrm{kV}$ single bus zone substation, having process bus architecture, reliability and performance of the communication network could be enhanced. The simulation validated the speed of frames arriving at nodes as per the IEC 61850-9-2 standard.

\section{REFERENCES}

[1] L-F. Santos, "Substation Automation Process Bus system design and experience with IEC 61850-9-2 and NCIT's", presentation by ABB group, August, 2012.

[2] M. G. Kanabar and T. S. Sidhu. "Performance of IEC 61850-9-2 Process bus and corrective measure for digital relaying", IEEE Trans. on Power Del., vol. 26, no 2, pp. 725-735, Apr. 2011.

[3] T. S. Sidhu and P. K. Gangadharan, "Control and automation of power system substation using IEC61850 communication", in Proc. of 2005 IEEE Conference on Control Applications, Toronto, Canada, Aug. 28-31, 2005.

[4] IEEE PSRC Tech Rep., "Application consideration of IEC 61850/UCA2 for substation Ethernet local area network communication for protection and control" July 2005.

[5] P. M. Kanabar, M. G. Kanabar, W. E. Khattam, and T. S. Sidhu, "Evaluation of Communication Technologies for IEC 61850 based Distribution Automation System with Distributed Energy Resources." in proc. of the IEEE Power \& Energy Society General Meeting, 2009.

[6] M. J. G. Redondo, A. M. Munoz, V. P. Lopez, R. J. Calvo, and I. M. M. Garcia, "Testing transfer time in development stage for IEC 61850 based IED's", International virtue conference, Advanced Research in Scientific Areas 2012. Available: http://www.arsa-conf.com.

[7] M. G. Kanabar and T. S. Sidhu, "Packet scheduling of GOOSE messages in IEC 61850 based substation intelligent electronics devices (IED's)." in proc. Power \& Energy Society General Meeting, 2010.

[8] L. Andersson, K.P. Brand, C. Brunner, and W. Wimmer, "Reliability Investigation for SA communication architectures based on IEC 61850," in proc. of the Power Tech., 2005, Russia.

[9] P. Zhang, L. Portillo, and M. Kezunovic, "Reliability and Component Importance Analysis of All - Digital Protection Systems," in proc. of the IEEE Power Systems Conf. and Expo., pp. 1380-1387, 2006.

[10]IEC 61850 Communication Networks and Systems in Substations, 2004, $1^{\text {st }} \mathrm{Ed}$.

[11]C. Hoga, "New Ethernet Technologies for Substation Automation", Powertech 2007, Lusanne, AB, Canada. 